\title{
Collagenous sprue
}

Hugh James Freeman MD

HJ Freeman. Collagenous sprue. Can J Gastroenterol 2011;25(4):189-192.

Collagenous sprue is a small bowel mucosal lesion that has been historically associated with persistent diarrhea, progressive weight loss and severe malabsorption causing multiple nutrient deficiencies. A severe to variably severe mucosal lesion with distinct subepithelial collagen deposits occurs. Celiac disease has been intimately linked to collagenous sprue and, similar to celiac disease, small bowel ulceration, perforation and lymphoma may complicate the clinical course of collagenous sprue. In collagenous sprue, concomitant collagen deposits may also occur in gastric or colonic mucosal sites (or both), indicating that this unusual mucosal process may be very heterogeneous and far more extensive in the intestinal tract than previously appreciated. Moreover, reports of diagnosis during infancy suggest that the natural history of the disorder could be more prolonged than is currently appreciated. Finally, the collagen deposits, per se, may be due to different causes and, in some, even represent a novel paraneoplastic histopathological marker. Future studies are needed to more precisely define molecular and genetic biomarkers that identify homogeneous groups and permit the development of improved treatment strategies for this increasingly recognized disorder.

Key Words: Celiac disease; Collagenous sprue; Malabsorption; Refractory celiac disease; Sprue-like intestinal disease; T cell lymphoma

n 1970, Weinstein et al (1) described a small bowel biopsy lesion in a middle-age woman initially believed to have celiac disease. Although the typical 'flattened' biopsy appearance of untreated celiac disease was present, a long-term response to a gluten-free diet failed to occur. Later, hematoxylin and eosin-stained biopsies showed a prominent band-like deposit of subepithelial hyaline material with the histochemical features of collagen. Ultrastructural studies confirmed an electron-dense material with the typical $640 \mathrm{~A}$ axial periodicity of collagen fibres. Later, the patient developed worsening diarrhea, severe

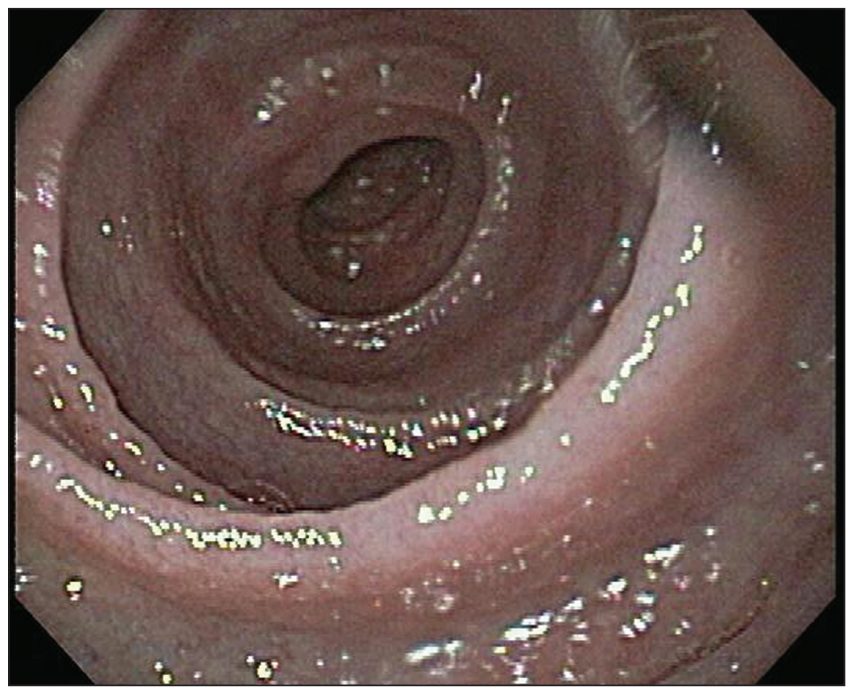

Figure 1) Endoscopic view of descending duodenum in collagenous sprue showing relatively feature-less mucosa with nonspecific loss of vascular pattern. Slight mucosal scalloping present

\section{La sprue collagène}

La sprue collagène est une lésion muqueuse de l'intestin grêle qui s'associe à une diarrhée persistante, à une perte de poids progressive et à une malabsorption marquée entraînant de multiples carences nutritives. On observe une lésion muqueuse grave à variable accompagnée de collagène sous-épithélial distinct. La maladie coliaque est intimement liée à la sprue collagène et, à l'instar de cette maladie, des ulcérations, des perforations et des lymphomes de l'intestin grêle peuvent en compliquer l'évolution clinique. En présence de sprue collagène, des dépôts concomitants de collagène peuvent également se déclarer dans des foyers muqueux gastriques ou coliques (ou les deux), ce qui démontre la grande hétérogénéité possible de ce processus muqueux inhabituel et la possibilité qu'il soit beaucoup plus étendu dans le tractus intestinal qu'on le croyait auparavant. De plus, des comptes rendus de diagnostic pendant la première enfance laissent supposer que l'évolution naturelle du problème pourrait être plus prolongée qu'on le croyait jusqu'à maintenant. Enfin, les dépôts mêmes de collagène peuvent être attribuables à diverses causes et, chez certains, représenter un nouveau marqueur histopathologique paranéoplasique. D'autres études s'imposent pour définir avec plus de précision les biomarqueurs moléculaires et génétiques qui permettent de repérer les groupes homogènes et pour élaborer de meilleures stratégies thérapeutiques à l'égard de ce trouble de plus en plus reconnu.

malabsorption and progressive weight loss. Postmortem studies showed extensive pathological changes, particularly in the proximal small bowel. These deposits varied in thickness and short segments of normal mucosa were also seen, especially in the distal small bowel. Reports by Schein (2) in 1947 and Hourihane (3) in 1963 were noted, while others (4) suggested that subepithelial collagen in celiac disease may simply represent a marker of poor prognosis. Subsequently, endoscopic changes have been noted, but are usually nonspecific (Figures 1 and 2), while pathological changes may vary in severity with a patchy distribution (Figure 3).

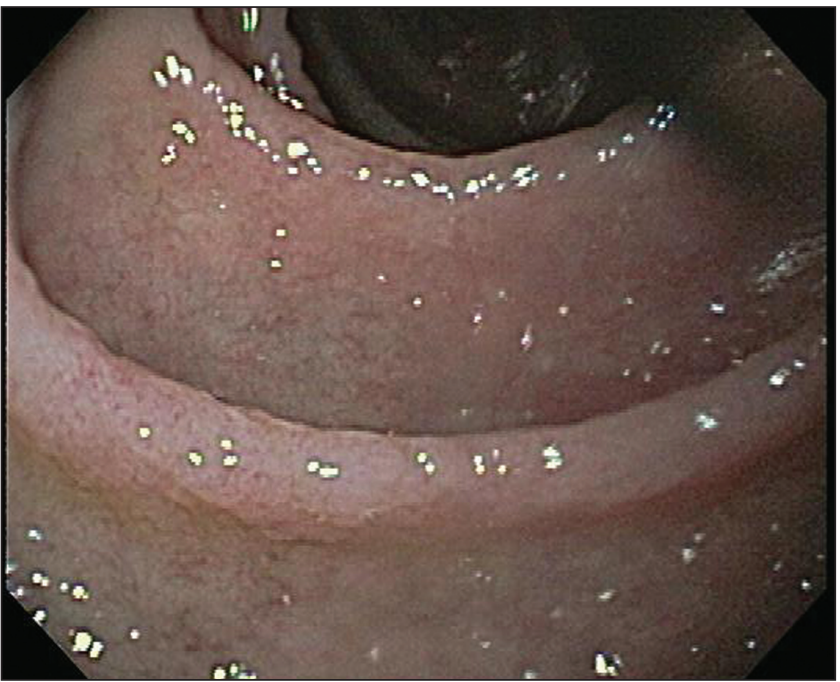

Figure 2) Endoscopic view of duodenal bulb in collagenous sprue showing pale mucosal appearance with slight mucosal scalloping. Nonspecific and patchy loss of vascular pattern is evident

Department of Medicine, Division of Gastroenterology, University of British Columbia, Vancouver, British Columbia

Correspondence: Dr Hugh James Freeman, Division of Gastroenterology, University of British Columbia Hospital, 2211 Wesbrook Mall, Vancouver,

British Columbia V6T 1W5. Telephone 604-822-7216, fax 604-822-7236, e-mail hugfree@shaw.ca

Received for publication December 24, 2009. Accepted October 6, 2010 


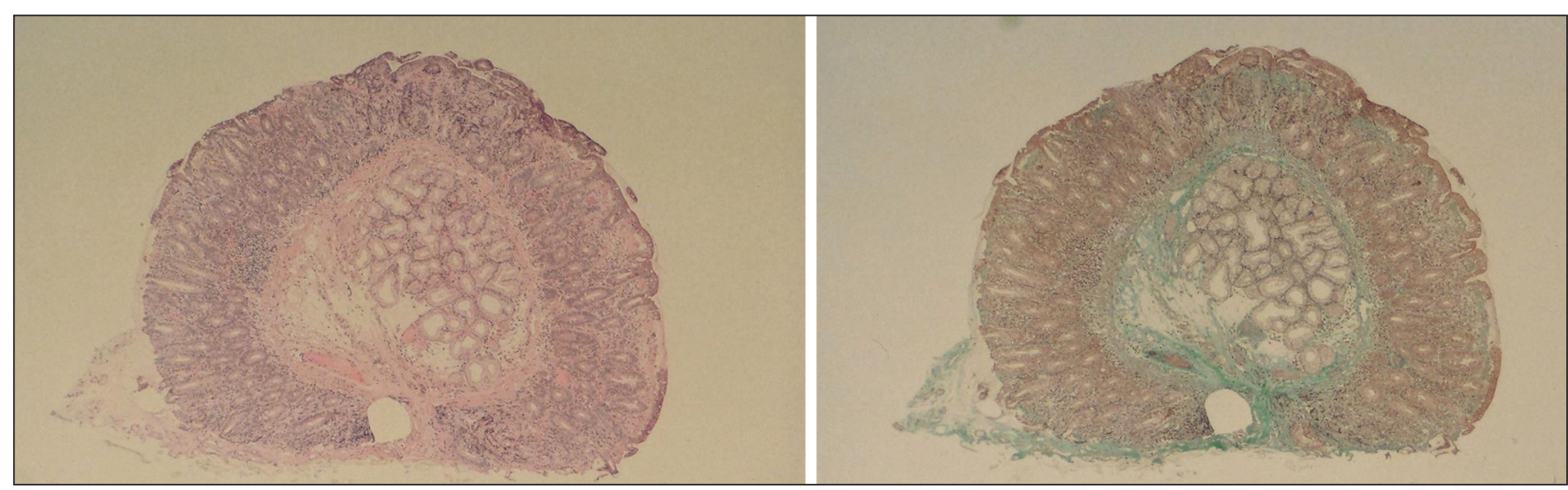

Figure 3) Photomicrographs of parallel biopsy sections from a duodenal bulb (note Brunner's glands in the submucosa) in collagenous sprue. The left panel is stained with hematoxylin and eosin, and the right panel is stained with trichrome. Subepithelial hyaline material is evident and also stains with trichrome. The subepithelial desposits are patchy in distribution and vary in thickness, even in the same biopsy. Inflammatory cells are trapped in the deposits, and the surface epithelium is separated in some areas from the underlying deposits. Reproduced with permission from reference 16

The clinical and pathological features of collagenous sprue include the following: first, the presence of persistent diarrhea with panmalabsorption causing multiple nutrient deficiencies and progressive weight loss that fail to respond to a gluten-free diet; and second, detection of a distinct proximal small bowel mucosal lesion with a unique morphological marker, a subepithelial band-like collagen deposit, usually with inflammatory cells 'trapped' in the deposit, along with characteristic 'separated' or sloughed surface epithelial cells.

\section{'REFRACTORY' MUCOSAL DISEASE}

Traditionally, celiac disease (or gluten-sensitive enteropathy) has been a pathologically based diagnosis. Two sequential criteria have been historically required: first, typical histopathological changes of untreated celiac disease in proximal small bowel biopsies and, second, a response to a gluten-free diet.

The clinical response may be dramatic, with resolution of diarrhea and significant weight gain. A 'flat' biopsy appearance may completely normalize, but in some patients, the response to a gluten-free diet may be difficult to define or cannot be documented. A histopathological response may require months to years (5), especially in elderly patients (6). Some have labelled these cases as refractory celiac disease; however, this term should be strictly reserved for individuals who show an initial - and documented - response to a gluten-free diet followed by recurrent symptoms and biopsy changes.

In celiac disease that becomes refractory to a gluten-free diet, causes include poor dietary compliance or inadvertent ingestion of a ubiquitous gluten-containing food source (eg, pill capsules and communion wafers). This is very common, and removal of the offending gluten source should be sufficient to resolve symptoms and biopsy changes. In celiac disease, a second or superimposed cause (eg, infection, folate or zinc deficiency) could also occur. Possibly, another entirely independent cause for a 'flat' biopsy lesion could be present (7) because the diagnosis may have been initially erroneous (eg, Crohn's disease in the duodenum without mucosal granulomas) (8). Finally, an associated or complicating illness (eg, collagenous colitis or lymphoma) may develop.

Another important 'wastebasket' group with 'flattened' biopsies may be seen: so-called sprue-like intestinal disease or unclassified sprue $(9,10)$. This is a heterogeneous group that appears to be completely refractory from the outset without evidence of any improvement despite a strict gluten-free diet. It is likely that there are multiple causes. Some have previously unrecognized collagenous sprue with the distinct pathologically defined collagen deposits. Others may have an autoimmune enteropathic process with positive epithelial cell antibodies (11). Finally, some patients in this group with 'refractory' disease may eventually prove to have an occult or 'cryptic' lymphoma (10).

\section{CELIAC DISEASE LINKAGES}

Collagenous sprue may share some elements with celiac disease including: hyposplenism and seropositivity with immunoglobulin (Ig)A endomysial antibodies (12). Positive IgA tissue transglutaminase ( $\mathrm{tTG}$ ) antibodies were seen in a report of celiac disease complicated by collagenous sprue (although tTG antibodies actually resolved with a gluten-free diet before detection of collagenous sprue) (13). Finally, recognized complications of celiac disease (13) have been described in collagenous sprue, including small bowel ulceration and free perforation (14) as well as both T cell and B cell lymphomas $(15,16)$. Free perforation, dissection and mucosal 'fracturing' occurs in other collagenous mucosal diseases. In collagenous colitis, this has been described either as a spontaneous colonic perforation with peritonitis (17) or with endoscopic instrumentation $(18,19)$. In collagenous gastritis, similar changes have recently been recorded following air insufflation during endoscopic evaluation (20).

\section{HETEROGENEITY OF COLLAGEN LOCALIZATION}

If collagen deposits are found in the small bowel, similar deposits may be concomitantly present in colonic (ie, collagenous colitis) and/or gastric mucosa (ie, collagenous gastritis) (21). An inflammatory process with intraepithelial lymphocytosis may also occur in these different sites. Interestingly, collagenous or lymphocytic colitis as well as collagenous or lymphocytic gastritis have all been associated with biopsy-defined celiac disease (22-24). Indeed, collagenous colitis, if detected, should prompt exploration for underlying occult small bowel disease, particularly celiac disease (22). Similar findings have been independently confirmed $(25,26)$ along with a recent report showing these extensive histopathological changes in the accumulated experience by gastrointestinal biopsy pathologists from Europe, North America and Australia (27).

Because a far more extensive pathological process in the gastrointestinal tract may occur in collagenous sprue, detection of collagen deposits in the small bowel should prompt further endoscopic assessment and biopsy elsewhere in the gastrointestinal tract (27).

\section{NATURAL HISTORY}

Contemporary information is based predominantly on older adults. A recent case report (28), however, served to emphasize that even young infants may be affected before one year of age, implying that the 
natural history of this intriguing disorder could hypothetically extend over many decades. Most early case reports suggested that the natural history of collagenous sprue was limited and associated with a dismal prognosis, typically with progressive malabsorption and an inevitably fatal outcome. In most patients, diarrhea and progressive weight loss occur and, rarely, severe abdominal pain, sometimes with associated vasculitis, has been recorded (29). However, more recent and independent reports, with extensive biopsy studies $(30,31)$ have documented clinical resolution and pathological disappearance of the lesion for prolonged periods after corticosteroids or following additional treatment with immunosuppressive agents, suggesting that the lesion may be reversed, at least temporarily, for extended periods, even years. In addition, successful treatment with biological agents, such as infliximab, has been documented $(32,33)$, although reports describing development of lymphoproliferative diseases, particularly $\mathrm{T}$ cell type hepatosplenic lymphomas, may temper this treatment approach (34) because this malignancy also occurs in celiac disease (35). Interestingly, recent series $(36,37)$ have reported additional cases with positive clinical outcomes. Collectively, these reports suggest that some patients with these collagen deposits in the small intestine have the potential to clinically and histopathologically resolve. To date, however, no single clinical marker or pathological signature appears to predict which patients might be responsive to treatment.

\section{DISEASE HETEROGENEITY}

The pathogenesis of these collagen deposits is not understood, but different causes could be responsible. In addition to its intimate linkage with celiac disease, collagenous sprue has not only been complicated by T cell lymphoma $(15,16)$, but has been associated with its co-occurrence (38). Finally, collagen deposits in both the small and large intestine

\section{REFERENCES}

1. Weinstein WM, Saunders DR, Tytgat GN, Rubin CE.

Collagenous sprue - an unrecognized type of malabsorption. N Engl J Med 1970;283:1297-301.

2. Schein J. Syndrome of nontropical sprue with hitherto undescribed lesions of the intestine. Gastroenterology 1947;8:438-60.

3. Hourihane DO. The histology of intestinal biopsies. Proc R Soc Med 1963;56:1073-7.

4. Bossart R, Henry K, Booth CC, Doe WF. Subepithelial collagen in intestinal malabsorption. Gut 1975;16:18-22.

5. Freeman HJ, Whittaker JS. Non-alcoholic chronic pancreatitis with pancreatic calcification: Presenting manifestation of occult celiac disease. Can J Gastroenterol 1994;8:319-22.

6. Tursi A, Brandimarte G, Giorgetti GM, et al. Endoscopic and histological findings in the duodenum of adults with celiac disease before and after changing to a gluten-free diet: A 2-year prospective study. Endoscopy 2006;38:702-7.

7. Freeman HJ. Small intestinal mucosal biopsy for investigation of diarrhea and malabsorption in adults. Gastrointest Endosc Clin North Am 2000;10:739-53.

8. Schuffler MD, Chaffee RG. Small intestinal biopsy in a patient with Crohn's disease of the duodenum. The spectrum of abnormal findings in the absence of granulomas. Gastroenterology 1979;76:1009-14.

9. Freeman HJ. Refractory celiac disease and sprue-like intestinal disease. World J Gastroenterol 2008;14:828-30.

10. Perera DR, Weinstein WM, Rubin CE. Small intestinal biopsy. Hum Pathol 1975;6:157-217.

11. Freeman HJ. Adult autoimmune enteropathy. World J Gastroenterol 2008;14:1156-8.

12. Freeman HJ. Hyposplenism, antiendomysial antibodies and lympocytic colitis in collagenous sprue. Can J Gastroenterol 1999;13:347-50.

13. Freeman HJ, Webber DL. Free perforation of the small intestine in collagenous sprue. World J Gastroenterol 2009;15:4446-8.

14. Freeman HJ. Free perforation due to intestinal lymphoma in biopsy-defined or suspected celiac disease. J Clin Gastroenterol 2003;37:299-302.

15. Robert ME, Ament ME, Weinstein WM. The histologic spectrum and clinical outcome of refractory and unclassified sprue. Am J Surg Pathol 2000;24:676-87. were detected with an apparently coincidental, but localized, colon cancer (39). Later, clinical changes resolved and histopathological changes completely resolved after the cancer was resected, suggesting that these collagen deposits represent a paraneoplastic morphological marker of occult malignant disease. Indeed, collagen deposits in the stomach or intestine could be due to celiac disease, but may also represent a more generalized pathological response to different causes.

Collagenous sprue is a very heterogeneous disorder as reflected in concomitant collagen deposition in gastric and colonic mucosa in some cases, its recognition at different ages from infancy to old age, and its close linkage with celiac disease and recognition with different malignancies.

\section{FUTURE DIRECTIONS}

Recent studies suggest that these collagenous changes may be associated with different disorders, and may be more heterogeneous than previously appreciated as reflected in variable mucosal inflammatory changes with similar deposits elsewhere in the gastrointestinal tract, different responses to treatment and its association with other conditions including malignant disease as a possible paraneoplastic morphological marker.

Unfortunately, treatment remains an empirical and often frustrating clinical exercise. In part, this likely reflects the heterogeneity of the disorder. Its rare occurrence also poses a difficulty for any single physician or centre to accumulate significant treatment expertise. Future investigative endeavours that produce precise molecular and genetic markers are needed to permit definition of homogeneous forms of collagenous sprue that enable more specific avenues of therapy.

16. Freeman HJ. Collagenous sprue associated with an extensive T-cell lymphoma. J Clin Gastroenterol 2003:17:111-3.

17. Freeman HJ, James D, Mahoney CJ. Spontaneous peritonitis from perforation of the colon in collagenous colitis. Can J Gastroenterol 2001;15:265-7.

18. Mitchell JD, Teague R, Bolton R, Lowes J. Submucosal "dissection" in collagenous colitis. Gut 2004:53:470.

19. Sherman A, Ackert JJ, Rajapaksa R, West AB, Oweity T. Fractured colon: An endoscopically distinctive lesion associated with colonic perforation following colonoscopy in patients with collagenous colitis. J Clin Gastroenterol 2004;38:341-5.

20. Kuo P, Pieterse S, Harley HA. The stomach that "cracked" under pressure. Gastroenterology 2010;138:44.

21. Freeman HJ. Collagenous mucosal inflammatory diseases of the gastrointestinal tract. Gastroenterology 2005;129:338-50.

22. Freeman HJ. Collagenous colitis as the presenting feature of biopsy-defined celiac disease. J Clin Gastroenterol 2004;38:664-8.

23. Wolber R, Owen D, Del Buono L, Appelman H, Freeman HJ. Lymphocytic gastritis in patients with celiac sprue and sprue-like intestinal disease. Gastroenterology 1990;98:310-5.

24. Wolber R, Owen D, Freeman HJ. Colonic lymphocytosis in patients with celiac sprue. Hum Pathol 1990;21:1092-6.

25. Leung ST, Chandan VS, Murray JA, Wu TT. Collagenous gastritis: Histopathologic features and association with other gastrointestinal diseases. Am J Surg Pathol 2009;33:788-98.

26. Kao KT, Pedraza BA, McClune AC, et al. Microscopic colitis: A large retrospective analysis from a health maintenance organization experience. World J Gastroenterol 2009;15:3122-7.

27. Maguire AA, Greenson JK, Lauwers GY, et al. Collagenous sprue. A clinicopathologic study of 12 cases. Am J Surg Pathol 2009;33:1440-9.

28. Billiemaz K, Robles-Medranda C, Le Gall C, et al. A first report of collagenous gastritis, sprue, and colitis in a 9-month-old infant: 14 years of clinical, endoscopic, and histologic follow-up. Endoscopy 2009;41(Suppl 2):E233-E234.

29. Doe WF, Evans D, Hobbs JR, Booth CC. Celiac disease, vasculitis and cryoglobulinemia. Gut 1972;13:112-23.

30. Schreiber FS, Eidt S, Hidding M, Schmidt-Walczuch J, Werning C. Collagenous duodenitis and collagenous colitis: A short clinical course as evidenced by sequential endoscopic and histologic findings. Endoscopy 2001;33:55. 
31. Freeman HJ, Davis JE, Myers DM. Complete histologic resolution of collagenous sprue. Can J Gastroenterol 2004;18:333-6.

32. Schmidt C, Kasim E, Schlake W, Gerken G, Giese T, Stallmach A. TNF-alpha antibody treatment in refractory collagenous sprue: Report of a case and review of the literature. Z Gastroenterol 2009; 47:575-8.

33. Gillett HR, Arnott ID, McIntyre M, et al. Successful infliximab treatment for steroid-refractory celiac disease: A case report. Gastroenterology 2002;122:800-5.

34. Machy AC, Green L, Leang LC, Dinndorf P, Avigan M. Hepatosplenic T-cell lymphoma associated with infliximab use in young patients treated for inflammatory bowel disease. J Pediatr Gastroenterol Nutr 2007;44:265-7.

35. Freeman HJ. Fulminant liver failure with necrotizing foci in the liver, spleen and lymph nodes in celiac disease due to malignant lymphoma. Can J Gastroenterol 1996;10:225-9.
36. Vakiani E, Arguelles-Grande C, Mansukhani MM, et al. Collagenous sprue is not always associated with dismal outcomes: A clinicopathological study of 19 patients. Mod Pathol 2010;23:12-26.

37. Rubio-Tapia A, Talley NJ, Gurundu SR, Wu TT, Murray JA. Gluten-free diet and steroid treatment are effective therapy for most patients with collagenous sprue. Clin Gastroenterol Hepatol 2010;8:344-9.

38. Medlicott SA, Beck PL, Loken S, Crabtree T. Synchronous collagenous sprue and enteropathy-type $\mathrm{T}$ cell lymphoma: Variants of the same disease. Can J Gastroenterol 2004:18:329-32.

39. Freeman HJ, Berean KW. Resolution of paraneoplastic collagenous enterocolitis after resection of colon cancer. Can J Gastroenterol 2006;20:357-60. 


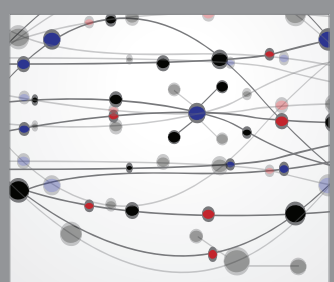

The Scientific World Journal
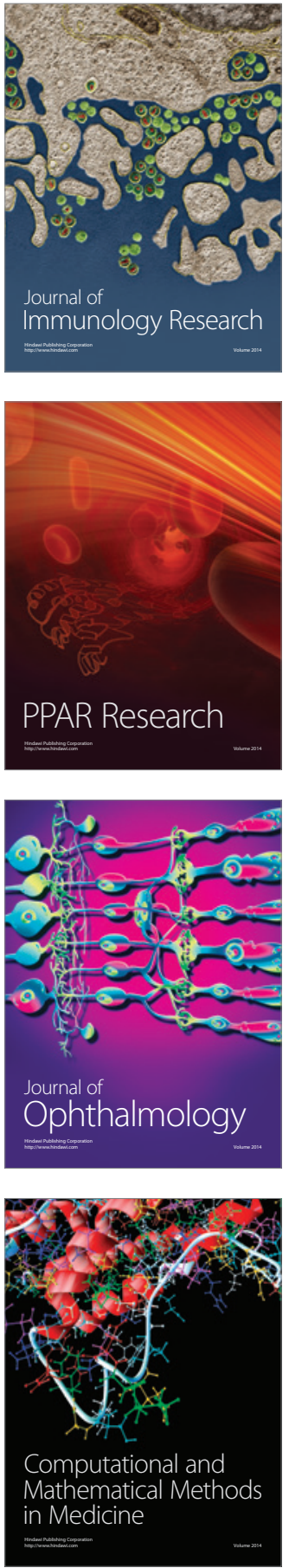

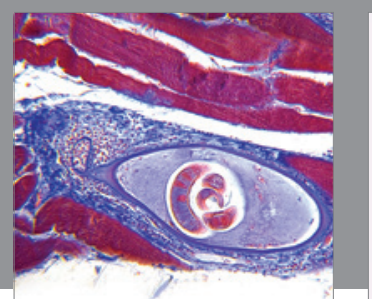

Gastroenterology Research and Practice

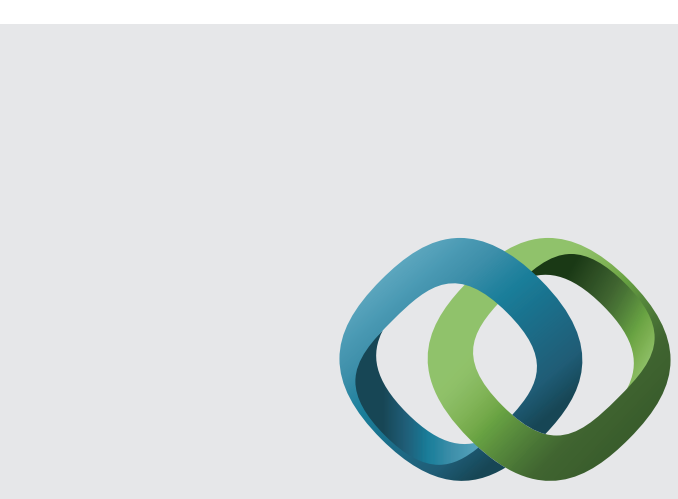

\section{Hindawi}

Submit your manuscripts at

http://www.hindawi.com
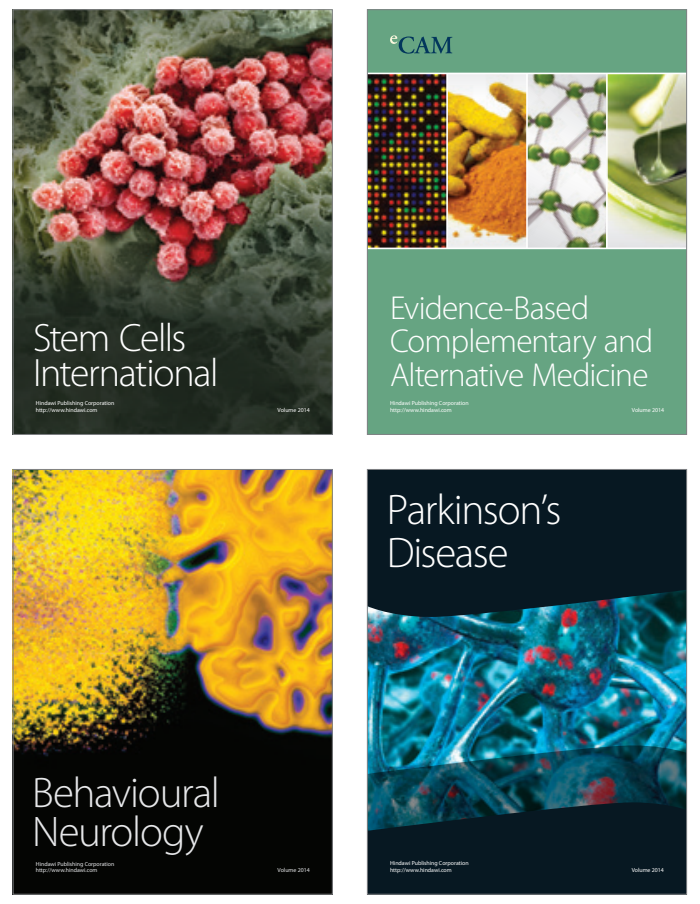
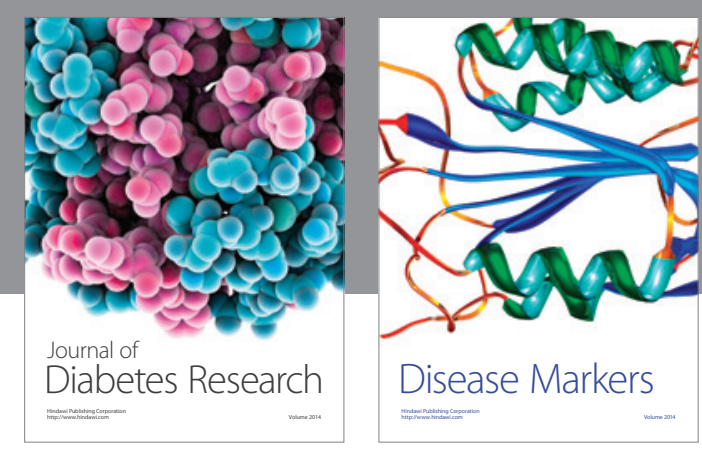

Disease Markers
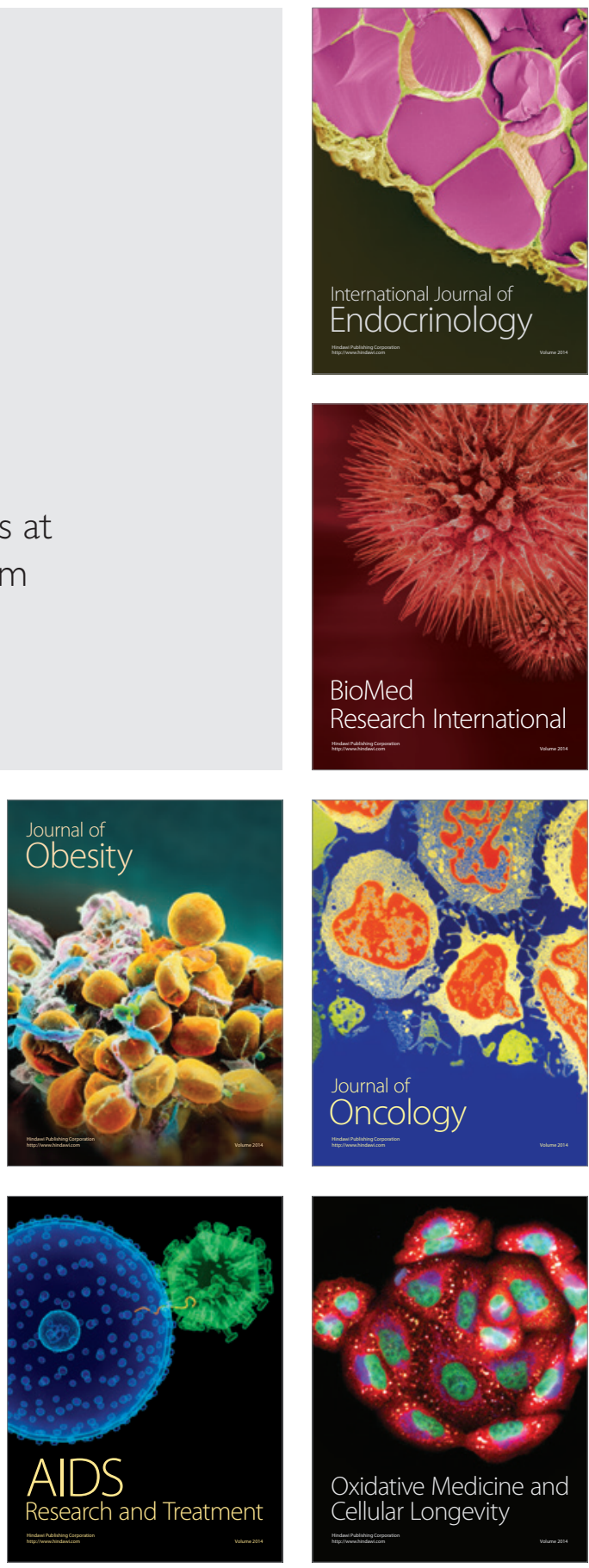